\title{
Follicular dendritic cell sarcoma of the pharyngeal region
}

\author{
TENGPENG HU ${ }^{1}$, XINHUA WANG ${ }^{1}$, CHANG YU $^{1}$, JIAQIN YAN ${ }^{1}$, XUNDONG ZHANG $^{1}$, LING $^{1}{ }^{1}$, \\ XIN LI $^{1}$, LEI ZHANG ${ }^{1}$, JINGJING WU ${ }^{1}$, WANG MA ${ }^{1}$, WENCAI LI $^{2}$, GUANNAN WANG ${ }^{2}$, \\ WUGAN ZHAO $^{2}$, XIANZHENG GAO ${ }^{2}$, DANDAN ZHANG ${ }^{2}$ and MINGZHI ZHANG ${ }^{1}$ \\ ${ }^{1}$ Lymphoma Diagnosis and Treatment Center, Department of Oncology; ${ }^{2}$ Department of Pathology, \\ The First Affiliated Hospital of Zhengzhou University, Zhengzhou, Henan 450052, P.R. China
}

Received November 1, 2012; Accepted February 4, 2013

DOI: $10.3892 / \mathrm{ol} .2013 .1224$

\begin{abstract}
Follicular dendritic cell sarcoma (FDCS) is a rare neoplasm arising most commonly from follicular dendritic cells in the lymph nodes. It is exceedingly rare in extranodal sites, particularly in the pharyngeal region. The present study reports 3 cases occurring in the pharyngeal region. Case 1 had tonsil and cervical lymph node involvement, while case 3 also had tonsil involvement. Cases 1 and 3 relapsed locally at 3 and 17 months after surgery, respectively. Case 2 was diagnosed with a tumor in the parapharyngeal space and the patient succumbed to the disease 5 months after treatment with combined surgery and chemotherapy. All 3 cases were misdiagnosed initially. Pathological biopsy examination, including histopathology and immunohistochemistry, was essential for diagnosis. The data for 52 cases, including cases from the literature and the present cases, were analyzed. The results indicated that $57 \%(26 / 46)$ of the initial diagnoses were inaccurate, while the recurrence, metastasis and mortality rates were 40,16 and $10 \%$, respectively. The statistics supported the theory that FDCS of the pharyngeal region is a low-grade sarcoma. Involvement of the tonsils $(52 \%, 27 / 52)$ and parapharyngeal space $(19 \%, 10 / 52)$ were observed most commonly, while FDCS at various sites showed different prognoses. The various survival rates were calculated in the present study. The large tumors $(\geq 4 \mathrm{~cm}$ ) had a poorer prognosis than the small tumors $(<4 \mathrm{~cm} ; \mathrm{P}<0.05)$. Among the 50 cases with available follow-up data, $46 \%(23 / 50)$ were treated with surgery alone, $52 \%(26 / 50)$ with combination therapy (surgery followed by chemotherapy and/or radiotherapy) and 2\% (1/50) with surveillance. There was no statistically significant evidence $(\mathrm{P}>0.05)$ that combination therapy improves survival rates, compared with surgery alone.
\end{abstract}

Correspondence to: Professor Mingzhi Zhang, Oncology Department, The First Affiliated Hospital of Zhengzhou University, 1 Jianshe Road, Zhengzhou, Henan 450052, P.R. China

E-mail: mingzhi_zhang@126.com

Key words: follicular dendritic cell sarcoma, pharyngeal, immunohistochemistry, surgery, radiotherapy, chemotherapy

\section{Introduction}

Follicular dendritic cells (FDCs) are non-lymphoid, non-phagocytic antigen-presenting cells of the immune system and are able to capture, process and present antigens and immune complexes to B and T cells. FDCs belong to the dendritic cell family which may be divided into 4 categories based on immunophenotypes: interdigitating dendritic, indeterminate, Langerhans and follicular dendritic cells (1). FDCs are normally located in the germinal centers of primary and secondary follicles where they form a tight meshwork with other cells. In addition, FDCs may be located extranodally in acquired lymphoid tissue which is the foundation condition for the occurrence of extranodal FDCS (2). The possibility of a follicular dendritic cell tumor was first suggested by Lennert in 1978 (3). A primary neoplasm of FDC origin in a lymph node was first described by Monda et al in 1986 (4), while the name, FDCS, was first proposed by Chan et al in 1997 (5).

FDCS is a rare neoplasm. At present, 200 cases have been reported in the English-language literature. The majority of cases were observed in lymph nodes and less than one-third were extranodal (6). The pharyngeal region, along with the abdominal/pelvic cavity, was one of the preferred sites of extranodal FDCS (7). The present study reports 3 cases of pharyngeal FDCS treated at the First Affiliated Hospital of Zhengzhou University (Zhengzhou, China) over the last 10 years. With regard to the diagnosis and therapeutic modalities, 49 cases reported in the English-language literature were reviewed.

\section{Materials and methods}

Samples. Tissue specimens from 3 patients, who were all treated at the First Affiliated Hospital of Zhengzhou University over the last decade, were collected and fixed in $10 \%$ buffered formalin, then dehydrated, embedded in paraffin and cut into 4- $\mu$ m-thick sections for hematoxylin and eosin (HE) staining and light microscopy.

Immunohistochemistry. Immunohistochemical reactions were performed on the paraffinized sections using the EnVision method. The diagnostic antibodies used included antibodies against CD21, CD23, CD35, podoplanin (D2-40), CXCL-13, 

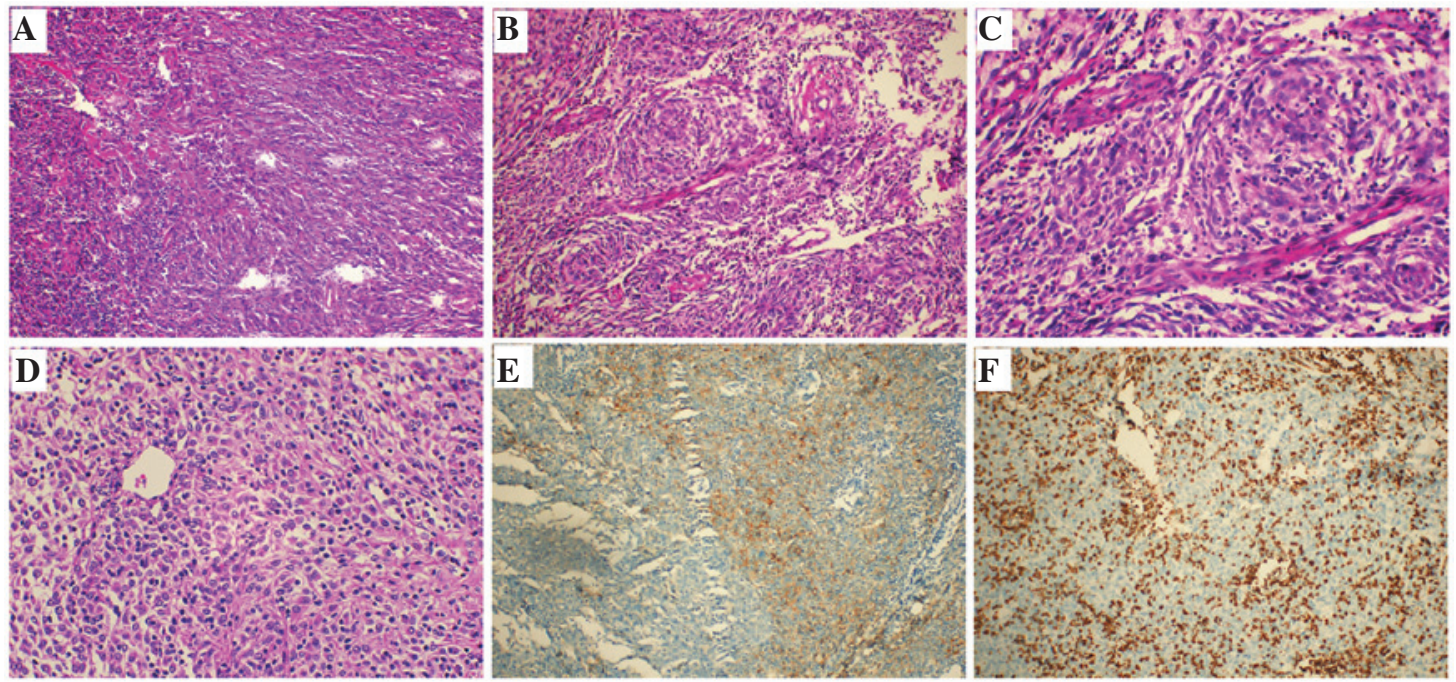

Figure 1. Pathological characteristics of pharyngeal FDCS. (A) Tumor cells arranged in a diffusing sheet-like distribution, partially in the storiform pattern (case 2). (B) Tumor cells arranged in the whorl pattern (case 3). (C) Indistinct cell borders and slightly eosinophil-stained cytoplasm of tumor cells. Infiltrating small lymphocytes and tissue cells were observed in the background (case 3). (D) Nuclei of tumor cells were irregular, round- or spindle-shaped, containing delicate chromatin and small nucleoli. Clear mitotic counts were observed (case 1). (E) Tumor cells were positive for podoplanin (case 3). (F) Tumor cells were negative for LCA, but the lymphocytes scattered in the background were positive for LCA (case 3). FDCS, follicular dendritic cell sarcoma; LCA, leukocyte common antigen.

S100 protein, vimentin, epithelial membrane antigen (EMA), cytokeratin (CK, AE1/AE3), CD163, leukocyte common antigen (LCA, CD45), CD1a, CD68, CD34, CD3 and CD20. Ki-67 (MIB-1) antigen was detected to show the proliferative activity of each lesion.

In situ hybridization. In situ hybridization for EBV-encoded RNA (EBER) was also performed on the formalin-fixed, paraffin-embedded tissue sections and the probes used were purchased from Beijing Zhongshan Golden Bridge (Beijing, China).

Literature review. A literature search was performed using MEDLINE on PubMed (www.ncbi.nlm.nih.gov/pubmed) with the term 'follicular dendritic cell sarcoma' combined with 'extranodal' and 'pharyngeal'. Efforts were made to identify cases that were reported more than once in various settings and only the entry with the most up-to-date information was included in such cases. Only FDCS of the pharyngeal region were included in Table III.

Statistical analysis. Statistical analyses were performed using the Statistical Analysis System (SAS) 9.2. Disease-free survival (DFS) and overall survival (OS) rates were analyzed using the Kaplan-Meier method. Log-rank tests were used to analyze the equality of survival function over strata. $\mathrm{P}<0.05$ was considered to indicate statistically significant differences.

\section{Results}

Clinical data. As shown in Table I, the 3 patients were all female, with ages ranging between 36 and 64 years (median, 59 years). Of the 3 cases, 2 were tonsil lesions with case 1 being a left-tonsil lesion with left cervical lymph node involvement, while case 3 was a left-tonsil lesion. Case 2 was a mass in the parapharyngeal space. A mass was detected in the oropharynx and slight dysphagia symptoms were experienced in all 3 cases. Tumor resection was performed in all 3 cases and the symptoms were relieved. The sizes of the tumors ranged between 3.0 and $6.0 \mathrm{~cm}$ as measured in the longitudinal dimension, with an average of $4.5 \mathrm{~cm}$. All the tumors were initially misdiagnosed as non-specific inflammation (case 1), a benign tumor (case 2) or squamous cell carcinoma (case 3).

There was only 1 patient (case 1) who remained alive in the follow-up 7 to 24 months. Case 2 succumbed to the disease 7 months after initial treatment with combined surgery and chemotherapy without recurrence. Case 3 succumbed 7 months after local recurrence despite a second resection followed by radiotherapy (200 cGy x 25 times; total 5,000 cGy). Case 1 relapsed locally in the left neck lymph nodes 6 months after surgery, then salvage therapy was performed, including 4 courses of the 'CHOP' adjuvant chemotherapy regimen according to the following schedule: cyclophosphamide $750 \mathrm{mg} / \mathrm{m}^{2}$ i.v (day 1), vincristine $1.4 \mathrm{mg} / \mathrm{m}^{2}$ i.v (day 1), doxorubicin $40 \mathrm{mg} / \mathrm{m}^{2}$ i.v (day 1) and prednisone $100 \mathrm{mg}$ p.o. (days 1-5) and 1 course of radiotherapy with a total of 5,600 cGy (200 cGy x 28 times). Subsequently, complete remission (CR) was achieved. The longest disease-free time (DFT) among the 3 present cases was 17 months.

Histopathology. In case 1, the tumor was confined by fibrous tissue and showed clear boundaries. The tumor cells were ovoid- to spindle-shaped and arranged in sheet-like or fascicular patterns. In case 2 , the tumor cells showed diffusing sheet-like distributions, partially in the storiform pattern, and were separated by collagenous fibers (Fig. 1A). In case 3, whorl structures formed by tumor cells were observed (Fig. 1B). In all 3 cases, irregular round or spindle nuclei, containing delicate chromatin and small nucleoli, were observed (Fig. 1D). Indistinct cell borders and slightly eosinophil-stained cytoplasm were the most common features. Infiltrating small lymphocytes and tissue cells were distributed in the background (Fig. 1C). 

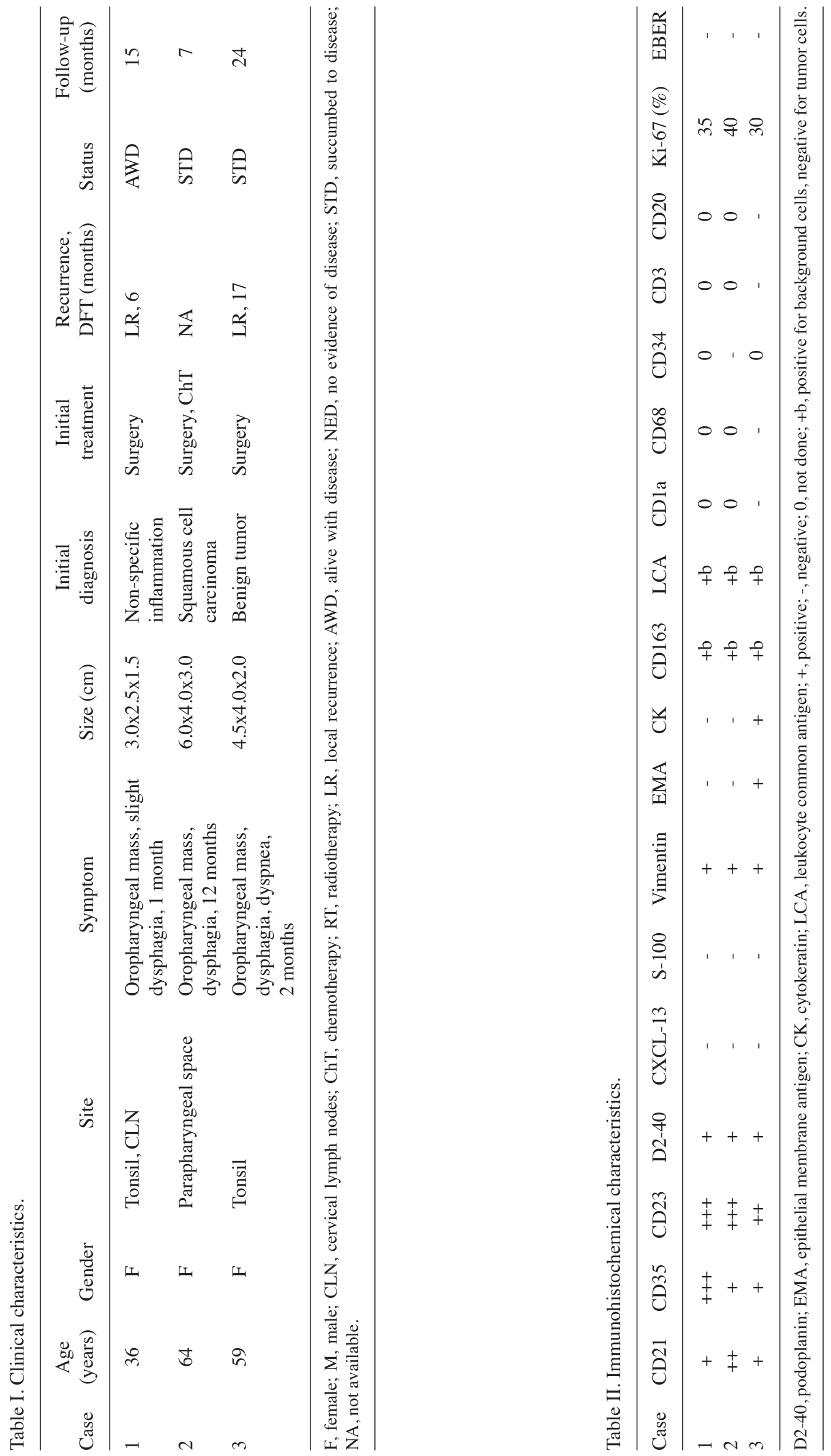

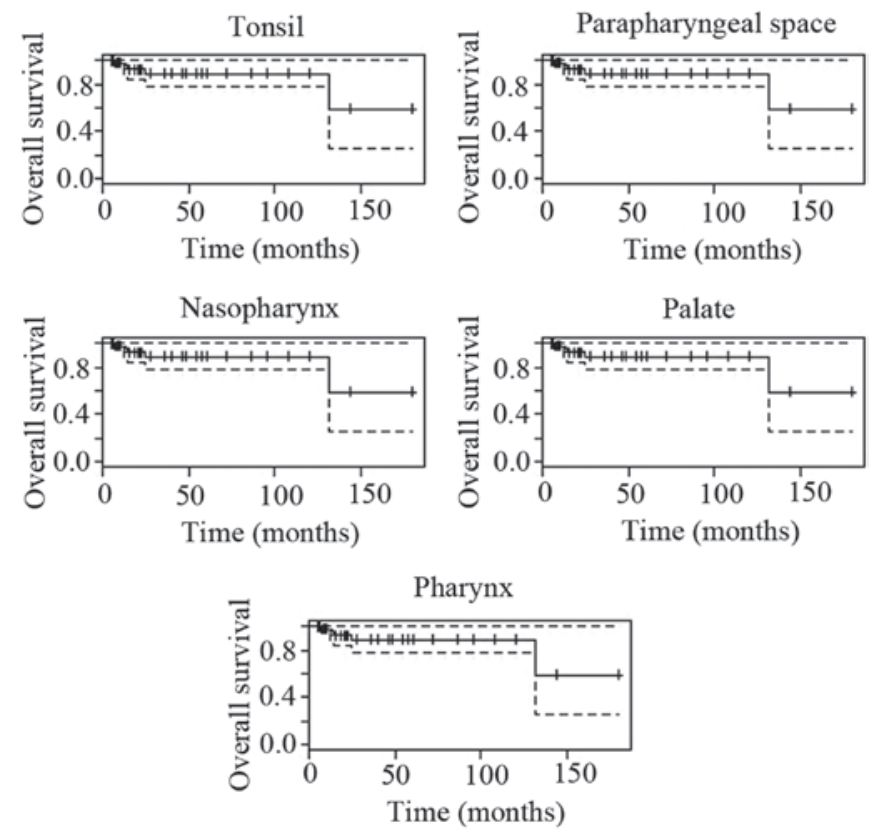

Figure 2. OS curves of pharyngeal FDCS at various sites. OS, overall survival; FDCS, follicular dendritic cell sarcoma.

Immunohistochemistry and in situ hybridization. As shown in Table II, the immunohistochemical stains in all 3 cases were positive for CD21, CD35, CD23 and vimentin, but negative for CK (positive minority in case 3) and S100 protein. The expression of D2-40 was observed in partial or focal tumor cells in all cases while CXCL-13 was absent (Fig. 1E). Case 1 was slightly positive for EMA. CD163 and LCA were positive in the background cells(Fig. 1F). The Ki-67-labeling index (Ki-67 LI) of all the lesions ranged between 30 and $40 \%$. Furthermore, the in situ hybridizations for EBER were negative in all cases. Certain antibodies were stained in 1 case but not stained in the others, as follows: in case 3, the immunohistochemical reaction for CD1a was negative, while CD3 and CD20 were positive in the background cells and negative in tumor cells; CD34 was negative in the tumor of case 2 .

Literature review of pharyngeal FDC sarcomas. The following summaries were obtained from a total of 52 cases of FDCS in the pharyngeal region, including the 3 present cases and 49 cases identified through a MEDLINE search (Table III).

The patients ranged between 14 and 77 years old (median, 48 years; average, 47 years). The female/male ratio was 1:1.08 (25:27). The tumors tended to occur in young to middle aged adults without any gender difference. The FDCSs occurred in various anatomical parts of the pharyngeal region. The most common site was the tonsils, with 27 cases (52\%). Other sites included the parapharyngeal space $(10 / 52,19 \%)$, nasopharynx $(8 / 52,15 \%)$, palate $(4 / 52,8 \%)$, pharynx $(2 / 52$, $4 \%)$ and hypopharynx $(1 / 52,2 \%)$. The tumors in the various anatomical regions showed distinct prognoses (Table IV) and their survival curves are shown in Figs. 2 and 3. The recurrence, metastasis and mortality rates in the tonsils were 30.8 , 15.4 and $3.9 \%$, respectively. Of the cases with metastasis, all
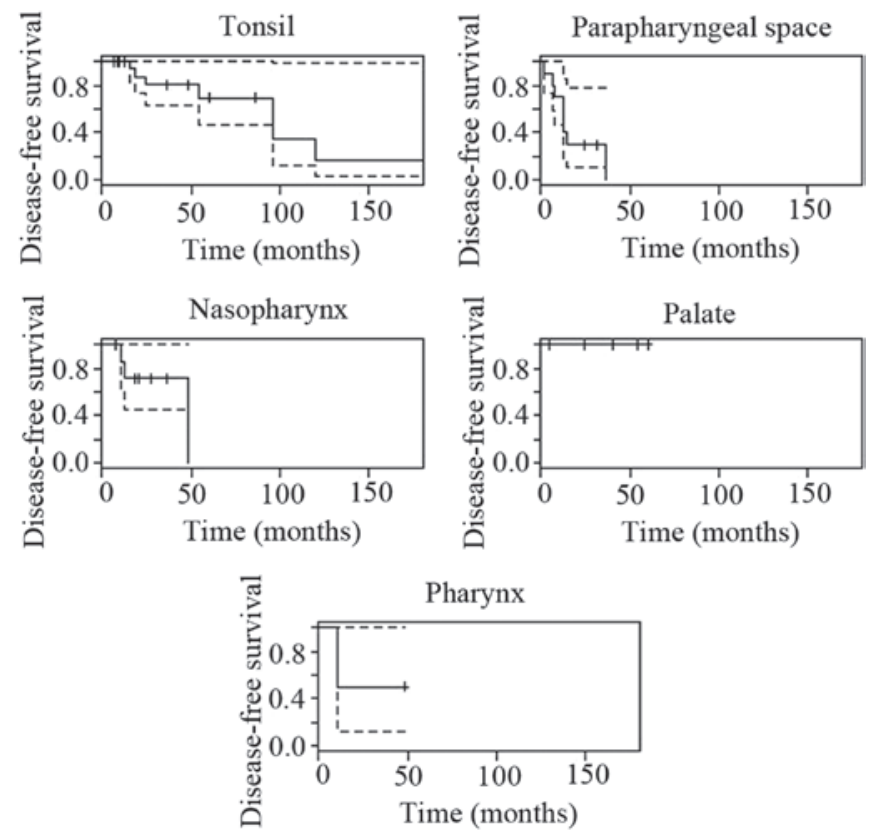

Figure 3. DFS curves of pharyngeal FDCS at various sites. DFS, disease-free survival; FDCS, follicular dendritic cell sarcoma.

$(4 / 4,100 \%)$ involved the cervical lymph nodes, while a number $(2 / 4,50 \%)$ also involved the lungs. The FDCSs in the parapharyngeal space showed the worst prognosis with recurrence, metastasis and mortality rates of 80,20 and $30 \%$, respectively. Furthermore, all the cases $(2 / 2,100 \%)$ of metastasis from the parapharyngeal space involved the lungs. Due to the limited number of cases, the results in Table IV remain to be confirmed by a larger-scale survey.

To assess the prognosis, the size of the initial tumor was analyzed. The sizes varied between 1 and $7 \mathrm{~cm}$, with an average of $3.4 \mathrm{~cm}$, in the longitudinal dimension. The large tumors $(\geq 4 \mathrm{~cm})$ accounted for $34 \%(12 / 35)$ of cases and had recurrence, metastasis and mortality rates of $58.3,8.3$ and $33.3 \%$, respectively. However, the small tumors $(<4 \mathrm{~cm}, 66 \%$, 23/35) exhibited recurrence, metastasis and mortality rates of 17.4, 0 and $0 \%$, respectively. The 2-year DFS and OS rates of the large tumors were 36.8 and $59.7 \%$, respectively, in the follow-up of 6 to 132 months, while those of the small tumors were 81.5 and $100 \%$ in the follow-up of 5 to 54 months.

Since the longest follow-up of the small tumors was 54 months ( $<60$ months), the 5-year DFS and OS rates were not suitable, while those of the large tumors were 36.8 and $59.7 \%$, respectively. Further statistical analysis of the size was performed among the 35 available tumors and indicated that large tumors $(\geq 4 \mathrm{~cm}$ ) had a poorer prognosis compared with small tumors $(<4 \mathrm{~cm})$ with regard to DFS $(\mathrm{P}=0.0446$, $\mathrm{P}<0.05)$ and $\mathrm{OS}(\mathrm{P}=0.0086, \mathrm{P}<0.05)$ rates (Table IV, Fig. 4C and D; Kaplan-Meier estimation, log-rank test). Notably, $58.3 \%$ of the large FDCSs (7/12) occurred in the parapharyngeal space, among which $85.7 \%$ (6/7) exhibited recurrence. To a certain degree, this accounted for the poor prognosis of tumors in the parapharyngeal space. While $41.2 \%$ of the large sarcomas $(5 / 12)$ occurred in the tonsils, only 1 case $(1 / 5,25 \%)$ locally relapsed. 


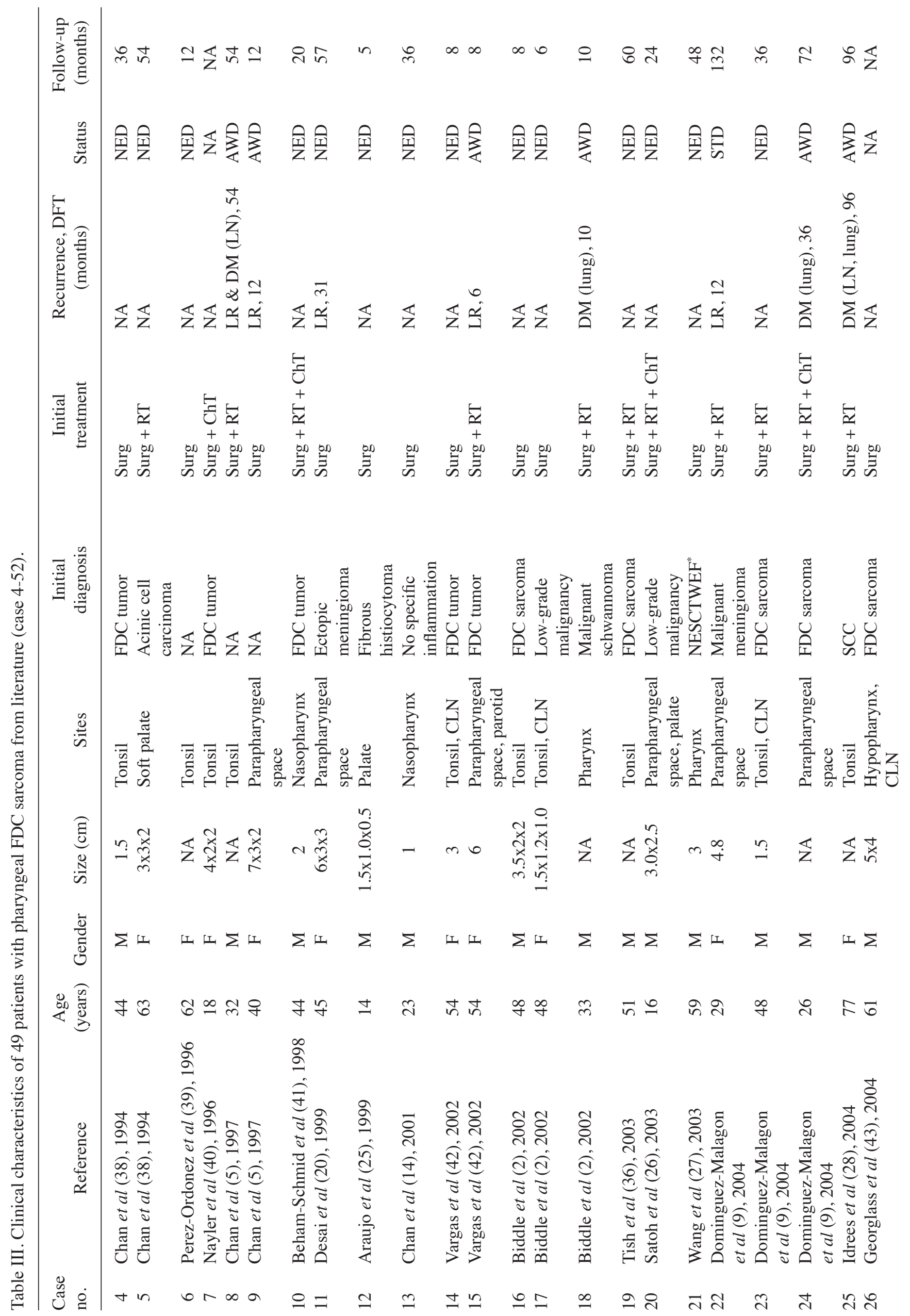




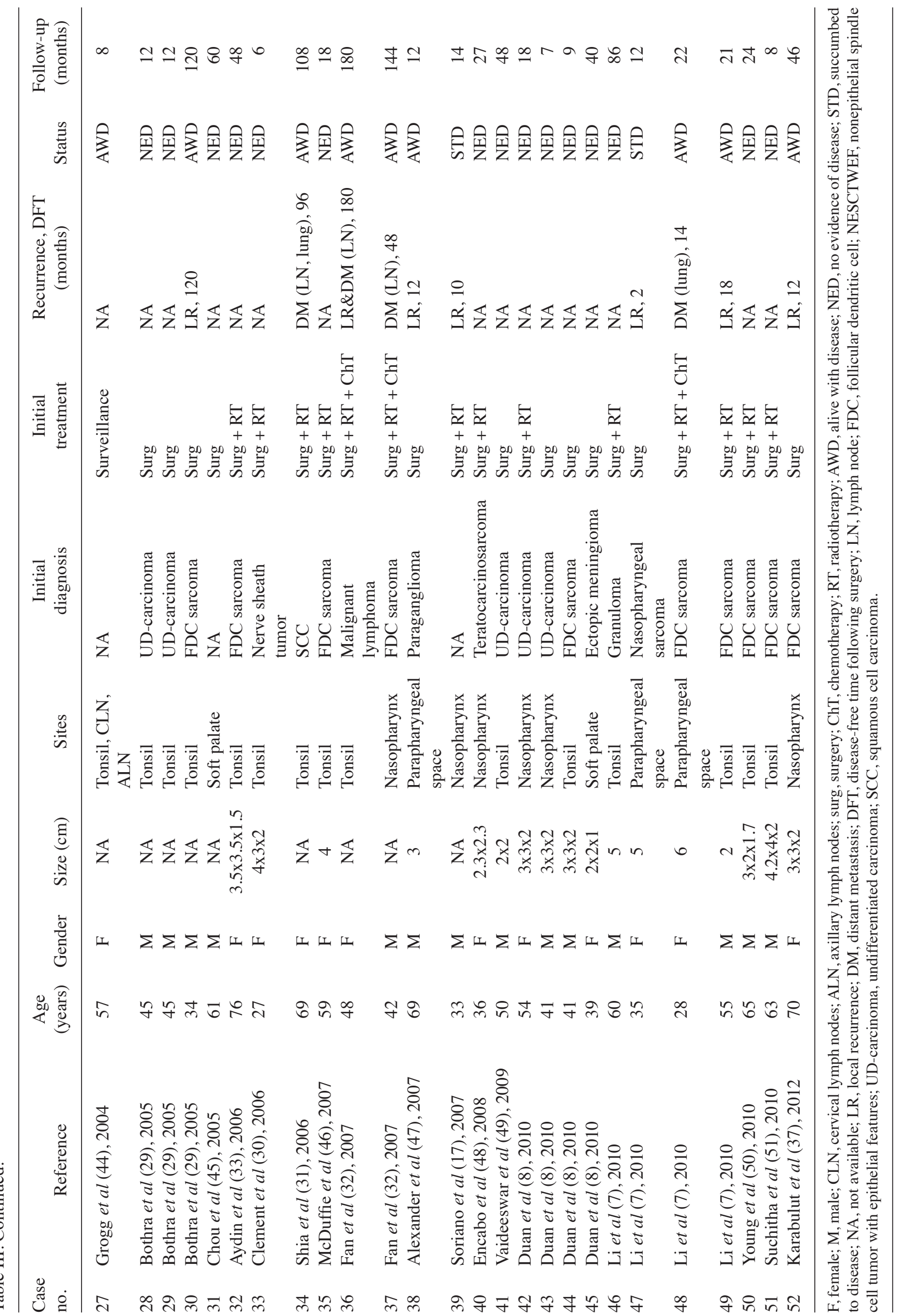




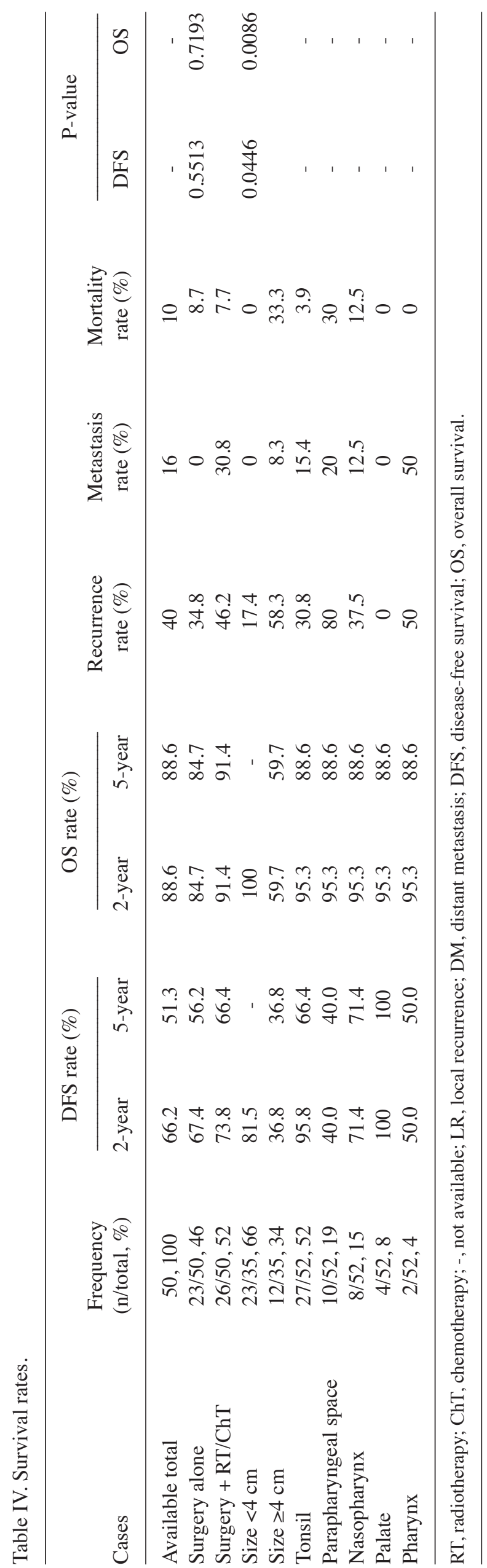

In the 50 cases with follow-up data, the follow-up time ranged between 5 and 180 months, with a median of 23 months and an average of 39 months. A total of 20 cases $(20 / 50,40 \%)$ relapsed, including $12(12 / 50,24 \%)$ of local recurrence and 8 $(8 / 50,16 \%)$ of distant metastasis. Additionally, 5 patients $(5 / 50$, $10 \%$ ) succumbed to the disease. The disease-free time varied from 2 to 180 months (median, 18 months; mean, 32 months). The recurrence, metastasis and mortality rates were 40, 16 and $10 \%$, respectively. The 2- and 5-year DFS rates for the entire group were 66.2 and $51.3 \%$, respectively, while the 2- and 5-year OS rates were 88.6 and $88.6 \%$, respectively (Kaplan-Meier estimation; Table IV, Fig. 4A and B).

Initially, nearly all the cases $(51 / 52,98.1 \%)$ underwent surgery to remove the tumor, with the exception of 1 case $(1 / 52,1.9 \%)$ where the patient opted to be surveilled. A total of 2 patients were lost to follow-up. Adjuvant treatment (radiotherapy and/or chemotherapy) was administered post-operatively to over half of the cases $(26 / 50,52 \%)$, among which $12(12 / 26,46 \%)$ suffered recurrence (local recurrence and/or metastasis), $8(8 / 26,31 \%)$ suffered metastasis (lung, lymph nodes) and $2(2 / 26,8 \%)$ succumbed to the disease in the follow-up of 6 to 180 months. For the group who received surgery and adjuvant therapy, the recurrence, metastasis and mortality rates were $46.2,30.8$ and $7.7 \%$, respectively. The 2and 5-year DFS rates were 73.8 and $66.4 \%$, respectively, while the 2- and 5-year OS rates were 91.4 and $91.4 \%$, respectively. Among the surgery alone group, recurrence was observed in 8 cases $(8 / 23,35 \%)$, no cases of metastasis were detected and 2 cases $(2 / 23,9 \%)$ succumbed to the disease in the follow-up of 5 to 120 months. The recurrence, metastasis and mortality rates were 34.8, 0 and $8.7 \%$, respectively. The 2- and 5-year DFS rates were 67.4 and $56.2 \%$, respectively, while the 2- and 5 -year OS rates were 84.7 and $84.7 \%$, respectively (Table IV). The disease-free time of patients who received adjuvant treatment (range, 6 to 180 months; mean, 39 months) was longer compared with the patients who received surgery alone (range, 2 to 120 months; mean, 24 months). However, the survival curves (Fig. 4E and F) suggested that the survival rates were not significantly different $(\mathrm{P}>0.05$, log-rank test).

\section{Discussion}

FDCS of the pharyngeal region is an extremely rare neoplasm which has been detected in the tonsils, palate, parapharyngeal space, nasopharynx, pharynx and hypopharynx, with the majority of distant metastasis occurring in the cervical or axillary lymph nodes and lungs (8). Similar to other body regions, pharyngeal FDCS occurs at a wide range of ages and has an adult predominance with equal gender distribution (9). The tumor usually presents as an enlarging solid mass and local pharyngeal disorders, including foreign body sensation, dysphagia, naso-obstruction and even intermittent bleeding (8).

The etiology and pathogenesis of FDCS are not clear. It is possible that certain FDCSs, particularly in hepatic and splenic lesions (10-12), are associated with EBV infection, although the association is not evident in pharyngeal tumors as the in situ hybridizations for EBV-encoded RNA were negative in the study by Duan et al (8), as well as the present study. Pauwels et al (13) and Chan et al (14) agreed that FDCS 

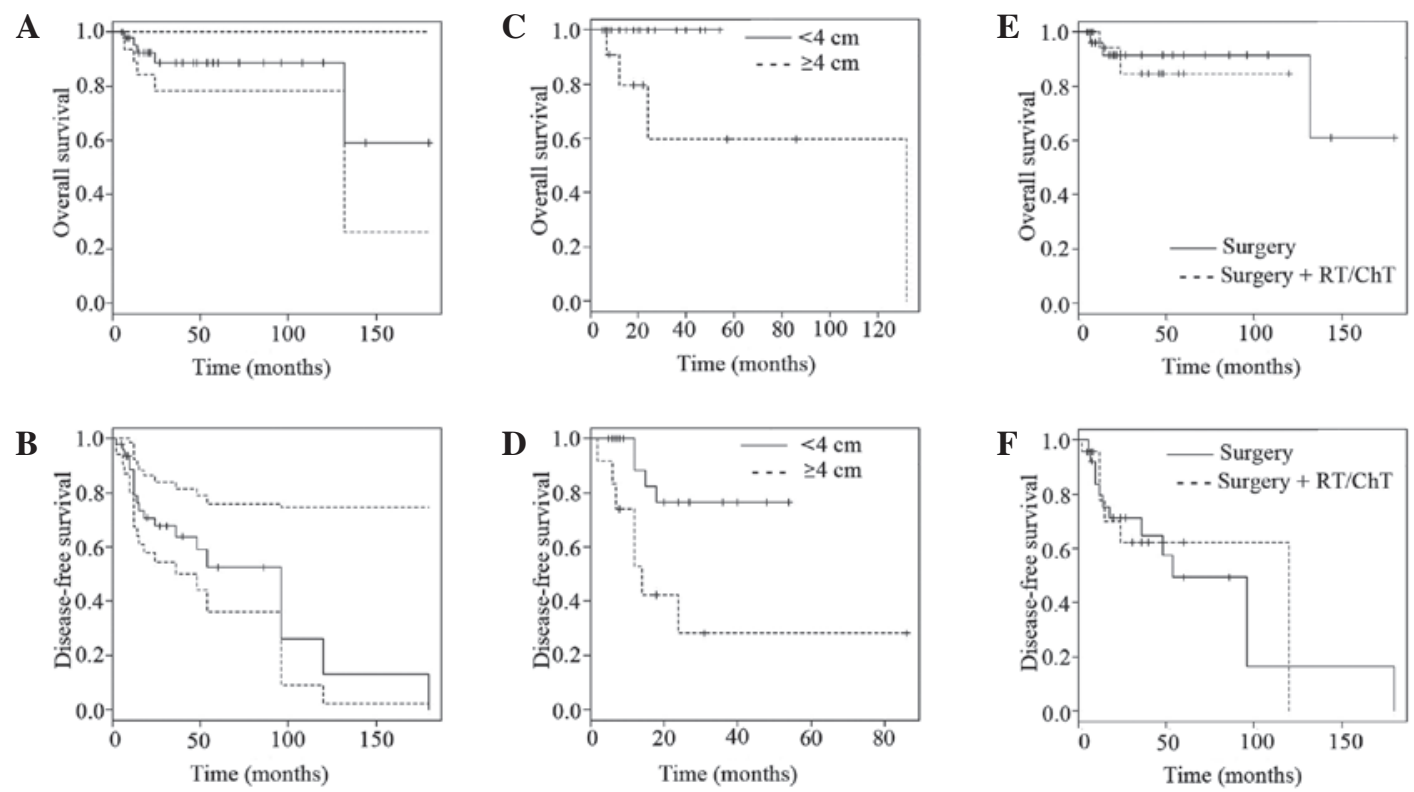

Figure 4. Survival curves of pharyngeal FDCS. (A) OS and (B) DFS curves of pharyngeal FDCS. (C) OS and (D) DFS curves of FDCS with various sizes ( $<4 \mathrm{~cm}$ or $\geq 4 \mathrm{~cm}$ in the longitudinal dimension). (E) OS and (F) DFS curves of FDCS with various treatments (surgery alone or surgery followed by RT and/or ChT). FDCS, follicular dendritic cell sarcoma; OS, overall survival; DFS, disease-free survival; RT, radiotherapy; ChT, chemotherapy.

developed according to a hyperplasia-dysplasia-neoplasia sequence in follicular dendritic cells.

The diagnosis of pharyngeal FDCS depends on pathology. Histologically, the typical lesion characteristics are whorl, storiform and fascicular arrangements of oval to spindle tumor cells with indistinct cell borders, possible syncytial growth patterns and pale eosinophilic cytoplasm $(5,15,16)$. Infiltrating small lymphocytes, which may gather around blood vessels, creating a cuffing pattern $(5,16)$, may be observed in the background. The nuclei of the tumor cells may be elongated or oval with delicate dispersed chromatin and small nucleoli $(5,16)$. The cells may also be multinucleated. Nuclear atypia and mitotic activity vary among different lesions $(5,16)$.

Due to the previously mentioned morphological variability, immunohistochemical confirmation is essential. As demonstrated in the literature, the most sensitive and specific markers for FDCS are CD21, CD23 and CD35 (17). They are consistently positive and should be the first-line markers. D2-40 and CXCL13 were also considered to be effective by Xie et al (18) and Vermi et al (19) and should be observed together with other immunohistochemical makers including vimentin, S-100 protein, EMA and CD68, which were variably positive $(17,20)$. CD1a, HMB45 and CD34 are specifically negative while CK is occasionally positive in FDCS $(2,15,21)$. Among the three present cases, CD21, CD23, CD35 and D2-40 were all distinctly positive. CD3 and CD20 (17) have been noted to be negative in FDC tumor cells but positive in the background lymphocytes, but were replaced by LCA (leukocyte common antigen) (20) and CD163 in the present study. Moreover, EGFR was observed to be overexpressed and may be a therapeutic target (17). Clusterin was reported to be an important marker in the differential diagnosis of FDCS (22). Several other variable antibodies, including desmoplakin, fascin, bcl-2 and p53 and certain nonspecific markers, including smooth muscle actin (SMA), CD30, lysozyme and myeloperoxidase
(MPO), are used clinically $(5,7,17,20,21,23,24)$. The Ki-67 antigen expression levels were low to moderate (15). EBER staining by in situ hybridization was negative in all pharyngeal FDCS cases, according to the statistics of Duan et al (8). In the three present cases, the Ki-67 LIs were 35, 40 and 30\%, respectively, and none of the cases were positive for EBER.

Misdiagnosis occurs frequently due to the rarity of pharyngeal FDCS tumors and similar histopathological characteristics shared with other common pharyngeal tumors, including ectopic meningioma, undifferentiated carcinoma, nerve sheath tumor, inflammatory sarcoma, squamous cell carcinoma, lymphoma and fibrous histiocytoma $(2,5,9,14,20,25-32)$. All three present cases were misdiagnosed. The misdiagnosis rate in the present survey was $57 \%$ (26/46), higher than the $30 \%$ reported by Shia et al (31) in the whole body. Among the mistaken diagnoses, ectopic meningioma accounted for $12 \%$ (3/26) and undifferentiated carcinoma for 19\% (5/26). Ectopic meningioma and FDCS feature syncytial cells arranged in whorl patterns and the tumor cells are negative for CK. However, lymphocytes and positive reactions for CD21, CD68 and CD35 are not observed in meningiomas (33). Similar to FDCS, undifferentiated carcinoma shows syncytial cells with vesicular nuclei and infiltrating lymphocytes. However, immunohistochemical markers positive for CD21, CD35 and CD23 and negative for CK, may be used to distinguish undifferentiated carcinoma from FDCS (8). Whenever pharyngeal tumors are identified, we recommend differential diagnosis and specific monoclonal antibody staining for FDCS.

FDCS is considered to be a sarcoma of intermediate-grade malignancy, which was demonstrated by Chan et al (5) in the observation of 17 cases. Prior to Chan et al's study, it was regarded as an indolent tumor similar to a low-grade soft tissue sarcoma with a tendency for local recurrence and a low risk of metastasis $(2,25)$. However, after analyzing 20 cases, Domínguez-Malagón et al (9) suggested that, in the pharyn- 
geal region, FDCS is a low-grade carcinoma with recurrence, metastasis and mortality rates of 25, 25 and 5\%, respectively. Duan et al (8) also suggested this and the rates of their 41-case analysis were 23,21 and $3 \%$, respectively. In the present study of 52 cases, the overall recurrence, metastasis and mortality rates were 40,16 and 10\%, respectively. The 2- and 5-year DFS rates were 66.2 and $51.3 \%$, respectively. This demonstrated that extranodal FDCS of the pharyngeal region remains low-grade with recurrence tendencies.

FDCSs of various anatomical sites in the pharyngeal region were also analyzed. The most common site was the tonsils, where $52 \%$ of all cases occurred. The site with the poorest prognosis was the parapharyngeal space, with recurrence, metastasis and mortality rates of 80,20 and $30 \%$, respectively. The recurrence, metastasis and mortality rates of FDCS at five sites were calculated and survival curves were shown for the first time. However, larger-scale research is required due to the limited number of cases in certain sites, particularly the nasopharynx, palate and pharynx.

As a result of the rarity of FDCS, the assessment of pharyngeal FDCS prognoses remains difficult. Li et al (7) proposed a model for recurrence risk assessment according to the tumor size and histological grade. By this model, extranodal FDC sarcomas were divided into low-, intermediate- and high-risk groups and the recurrence rates were 16,46 and $73 \%$, respectively, while the mortality rates were 0,4 and $45 \%$. In the present study, statistical analyses suggested that large tumors ( $\geq 4 \mathrm{~cm}$ in the longitudinal dimension) had a worse outcome compared with small tumors $(<4 \mathrm{~cm})$.

There is not yet a consensus with regard to the optimal therapeutic modality due to the limited number of case reports and absence of prospective studies of treatments and outcomes. Surgery or combination therapy (surgery followed by chemotherapy and/or radiotherapy) are the choices for the initial treatment. Radical surgery (dissection of nodal lesions or wide local excision of extranodal lesions) is essential for localized FDC tumors, as demonstrated by De Pas et al (34). Chera et al (35) analyzed 67 cases of FDCS in the head and neck region and recommended postoperative radiotherapy. The total doses ranged between 6,000 and 7,000 cGy. With regard to chemotherapy, the agents most commonly used are combination regimens designed for the treatment of non-Hodgkin's lymphoma, such as the CHOP (cyclophosphamide, doxorubicin, vincristine and prednisone) or CHOP-like regimens (36). Other regimens, such as sarcoma regimens, usually include a combination of doxorubicin and ifosfamide or gemcitabine, while a taxane may also be selected (17). Generally, 3 to 4 courses of chemotherapy were performed and partial or complete responses were achieved. However, it is not clear whether adjuvant treatment (chemotherapy and/or radiotherapy following surgery) is essential. Adjuvant treatment made no difference according to Duan et al (8) who analyzed 42 cases in the pharyngeal region. However, Karabulut et al (37) suggested that it was better to administer radiotherapy following resection to prevent local recurrence. According to the results of the present 52-case study, the average disease-free time of patients who underwent adjuvant treatment (range, 6 to 180 months; mean, 39 months) was longer compared with patients who underwent surgery alone (range, 2 to 120 ; mean, 24 months). The recurrence and mortality rates of the group who underwent surgery and adjuvant therapy were 46.2 and $7.7 \%$, respectively, while those of the surgery alone group were 34.8 and $8.7 \%$. However, the survival curves exhibited no statistically significant differences in DFS and OS rates between the two groups. From our clinical experience, postoperative adjuvant therapy appears to contribute to a longer disease-free time and is recommended. However, this remains to be clarified by larger-scale prospective studies of the treatments and outcomes of FDCS.

For accurate identification and effective therapy for FDCS, more attention should be paid to diagnosis and treatment.

\section{Acknowledgements}

The authors would like to thank Jian Chai (Social Medicine Research Center, Henan Provincial Population and Family Planning Reseach Institute, China) for performing the statistical analysis.

\section{References}

1. Favara BE, Feller AC, Pauli M, et al: Contemporary classification of histiocytic disorders. The WHO Committee On Histiocytic/Reticulum Cell Proliferations. Reclassification Working Group of the Histiocyte Society. Med Pediatr Oncol 29: 157-166, 1997.

2. Biddle DA, Ro JY, Yoon GS, Yong YW, Ayala AG, Ordonez NG and Ro J: Extranodal follicular dendritic cell sarcoma of the head and neck region: three new cases, with a review of the literature. Mod Pathol 15: 50-58, 2002.

3. Lennert K (ed): Malignant Lymphomas Other Than Hodgkin's Disease: Histology, Cytology, Ultrastructure, Immunology. Springer-Verlag, New York, NY, 1978.

4. Monda L, Warnke R and Rosai J: A primary lymph node malignancy with features suggestive of dendritic reticulum cell differentiation: a report of 4 cases. Am J Pathol 122: 562-572, 1986.

5. Chan JK, Fletcher CD, Nayler SJ and Cooper K: Follicular dendritic cell sarcoma: clinicopathologic analysis of 17 cases suggesting a malignant potential higher than currently recognized. Cancer 79: 294-313, 1997.

6. Youens KE and Waugh MS: Extranodal follicular dendritic cell sarcoma. Arch Pathol Lab Med 132: 1683-1687, 2008.

7. Li L, Shi YH, Guo ZJ, et al: Clinicopathological features and prognosis assessment of extranodal follicular dendritic cell sarcoma. World J Gastroenterol 16: 2504-2519, 2010.

8. Duan GJ, Wu F, Zhu J, Guo DY, et al: Extranodal follicular dendritic cell sarcoma of the pharyngeal region: a potential diagnostic pitfall, with literature review. Am J Clin Pathol 133: 49-58, 2010.

9. Domínguez-Malagón H, Cano-Valdez AM, Mosqueda-Taylor A and Hes O: Follicular dendritic cell sarcoma of the pharyngeal region: histologic, cytologic, immunohistochemical, and ultrastructural study of three cases. Ann Diagn Pathol 8: 325-332, 2004.

10. Cheuk W, Chan JK, Shek TW, et al: Inflammatory pseudotumor-like follicular dendritic cell tumor: a distinctive low-grade malignant intra-abdominal neoplasm with consistent Epstein-Barr virus association. Am J Surg Pathol 25: 721-731, 2001.

11. Chen TC, Kuo TT and Ng KF: Follicular dendritic cell tumor of the liver: a clinicopathologic and Epstein-Barr virus study of two cases. Mod Pathol 14: 354-360, 2001.

12. Bai LY, Kwang WK, Chiang IP and Chen PM: Follicular dendritic cell tumor of the liver associated with Epstein-Barr virus. Jpn J Clin Oncol 36: 249-253, 2006.

13. Pauwels P, Dal Cin P, Vlasved LT, Aleva RM, van Erp WF and Jones D: A chromosomal abnormality in hyaline vascular Castleman's disease: evidence for clonal proliferation of dysplastic stromal cells. Am J Surg Pathol 24: 882-888, 2000.

14. Chan AC, Chan KW, Chan JK, Au WY, Ho WK and Ng WM: Development of follicular dendritic cell sarcoma in hyaline-vascular Castleman's disease of the nasopharynx: tracing its evolution by sequential biopsies. Histopathology 38: 510-518, 2001. 
15. Pileri SA, Grogan TM, Harris NL, et al: Tumors of histiocytes and accessory dendritic cells: An immunohistochemical approach to classification from the International Lymphoma Study Group based on 61 cases. Histopathology 41: 1-29, 2002.

16. Perez-Ordoñez B and Rosai J: Follicular dendritic cell tumor: review of the entity. Semin Diagn Pathol 15: 144-154, 1998.

17. Soriano AO, Thompson MA, Admirand JH, et al: Follicular dendritic cell sarcoma: a report of 14 cases and a review of the literature. Am J Hematol 82: 725-728, 2007.

18. Xie Q, Chen L, Fu K, et al: Podoplanin (d2-40): a new immunohistochemical marker for reactive follicular dendritic cells and follicular dendritic cell sarcomas. Int J Clin Exp Pathol 1: 276-284, 2008

19. Vermi W, Lonardi S, Bosisio D, et al: Identification of CXCL13 as a new marker for follicular dendritic cell sarcoma. J Pathol 216: 356-364, 2008.

20. Desai S, Deshpande RB and Jambhekar N: Follicular dendritic cell tumor of the parapharyngeal region. Head Neck 21: 164-167, 1999.

21. Vaideeswar P, George SM, Kane SV, et al: Extranodal follicular dendritic cell sarcoma of the tonsil - case report of an epithelioid cell variant with osteoclastic giant cells. Pathol Res Pract 205: 149-153, 2009.

22. Grogg KL, Macon WR, Kurtin PJ and Nascimento AG: A survey of clusterin and fascin expression in sarcomas and spindle cell neoplasms: strong clusterin immunostaining is highly specific for follicular dendritic cell tumor. Mod Pathol 18: 260-266, 2005.

23. Orii T, Takeda H, Kawata S, Maeda K and Yamakawa M: Differential immunophenotypic analysis of dendritic cell tumours. J Clin Pathol 63: 497-503, 2010.

24. Cyriac S, Praveenkumar D, Majhi U and Sagar TG: Follicular dendritic cell sarcoma of the neck with an aggressive and fatal course. J Cancer Res Ther 6: 114-116, 2010.

25. Araújo VC, Martins MT, Salmen FS and Araújo NS: Extranodal follicular dendritic cell sarcoma of the palate. Oral Surg Oral Med Oral Pathol Oral Radiol Endod 87: 209-214, 1999.

26. Satoh K, Hibi G, Yamamoto Y, Urano M, Kuroda M and Nakamura S: Follicular dendritic cell tumor in the oro-pharyngeal region: report of a case and a review of the literature. Oral Oncol 39: 415-419, 2003.

27. Wang J, Kong Y, Lu H and Xu Y: Two cases of extranodal follicular dendritic cell sarcoma. Chin Med J (Engl) 116: 794-797, 2003.

28. Idrees MT, Brandwein-Gensler M, Strauchen JA, Gil J and Wang BY: Extranodal follicular dendritic cell tumor of the tonsil: report of a diagnostic pitfall and literature review. Arch Otolaryngol Head Neck Surg 130: 1109-1113, 2004.

29. Bothra R, Pai PS, Chaturvedi P, Majeed TA, Singh C, Gujral S and Kane SV: Follicular dendritic cell tumor of tonsil: is it an underdiagnosed entity? Indian J Cancer 42: 211-214, 2005.

30. Clement P, Saint-Blancard P, Minvielle F, Le Page P and Kossowski M: Follicular dendritic cell sarcoma of the tonsil: a case report. Am J Otolaryngol 27: 207-210, 2006.

31. Shia J, Chen W, Tang LH, et al: Extranodal follicular dendritic cell sarcoma: clinical, pathologic and histogenetic characteristics of an underrecognized disease entity. Virchows Arch 449: 148-158, 2006.

32. Fan YS, Ng WK, Chan A, Chan GS, Tsang J, Chim CS and Ip P: Fine needle aspiration cytology in follicular dendritic cell sarcoma: a report of two cases. Acta Cytol 51: 642-647, 2007.
33. Aydin E, Ozluoglu LN, Demirhan B and Arikan U: Follicular dendritic cell sarcoma of the tonsil: case report. Eur Arch Otorhinolaryngol 263: 1155-1157, 2006.

34. De Pas T, Spitaleri G, Pruneri G, et al: Dendritic cell sarcoma: an analytic overview of the literature and presentation of original five cases. Crit Rev Oncol Hematol 65: 1-7, 2008.

35. Chera BS, Orlando C, Villaret DB and Mendenhall WM: Follicular dendritic cell sarcoma of the head and neck: case report and literature review. Laryngoscope 118: 1607-1612, 2008.

36. Tisch M, Hengstermann F, Kraft K, von Hinüber G and Maier H: Follicular dendritic cell sarcoma of the tonsil: report of a rare case. Ear Nose Throat J 82: 507-509, 2003.

37. Karabulut B, Orhan KS, Guldiken Y and Dogan O: Follicular dendritic cell sarcoma of the nasopharynx. Int J Oral Maxillofac Surg 41: 218-220, 2012.

38. Chan JK, Tsang WY, Ng CS, Tang SK, Yu HC and Lee AW: Follicular dendritic cell tumors of the oral cavity. Am J Surg Pathol 18: 148-157, 1994.

39. Perez-Ordonez B, Erlandson RA and Rosai J: Follicular dendritic cell tumor: report of 13 additional cases of a distinctive entity. Am J Surg Pathol 20: 944-955, 1996.

40. Nayler SJ, Verhaart MJ and Cooper K: Follicular dendritic cell tumor of the tonsil. Histopathology 28: 89-92, 1996.

41. Beham-Schmid C, Beham A, Jakse R, Auböck L and Höfler G: Extranodal follicular dendritic cell tumour of the nasopharynx. Virchows Arch 432: 293-298, 1998.

42. Vargas H, Mouzakes J, Purdy SS, Cohn AS and Parnes SM: Follicular dendritic cell tumor: an aggressive head and neck tumor. Am J Otolaryngol 23: 93-98, 2002.

43. Georgalas C, Kanagalingam J, Gallimore A and O'Flynn P: Follicular dendritic cell sarcoma arising from the hypopharynx. J Laryngol Otol 118: 317-318, 2004.

44. Grogg KL, Lae ME, Kurtin PJ and Macon WR: Clusterin expression distinguishes follicular dendritic cell tumors from other dendritic cell neoplasms: report of a novel follicular dendritic cell marker and clinicopathologic data on 12 additional follicular dendritic cell tumors and 6 additional interdigitating dendritic cell tumors. Am J Surg Pathol 28: 988-998, 2004.

45. Chou YY, How SW and Huang CH: Follicular dendritic cell sarcoma of the soft palate. J Formos Med Assoc 104: 843-847, 2005.

46. McDuffie C, Lian TS, Thibodeaux J. Follicular dendritic cell sarcoma of the tonsil: a case report and literature review. Ear Nose Throat J 86: 234-235, 2007.

47. Alexander AA, Zapanta PE and Khan A: Diagnosis and recurrence of follicular dendritic cell sarcoma. Otolaryngol Head Neck Surg 137: 832-834, 2007.

48. Encabo RS, McHugh J, Carrau RL, Kassan A and Heron D: Follicular dendritic cell sarcoma of the nasopharynx. Am J Otolaryngol 29: 262-264, 2008.

49. Vaideeswar P, George SM, Kane SV, Chaturvedi RA and Pandit SP: Extranodal follicular dendritic cell sarcoma of the tonsil: case report of an epithelioid cell variant with osteoclastic giant cells. Pathol Res Pract 205: 149-153, 2009.

50. Eun YG, Kim SW and Kwon KH: Follicular dendritic cell sarcoma of the tonsil. Yonsei Med J 51: 602-604, 2010.

51. Suchitha S, Sheeladevi CS, Sunila R and Manjunath GV: Extra nodal follicular dendritic cell tumor. Indian J Pathol Microbiol 53: 175-177, 2010. 